\section{T-CELL HOMEOSTASIS}

\section{T-cell build-up and blockade}

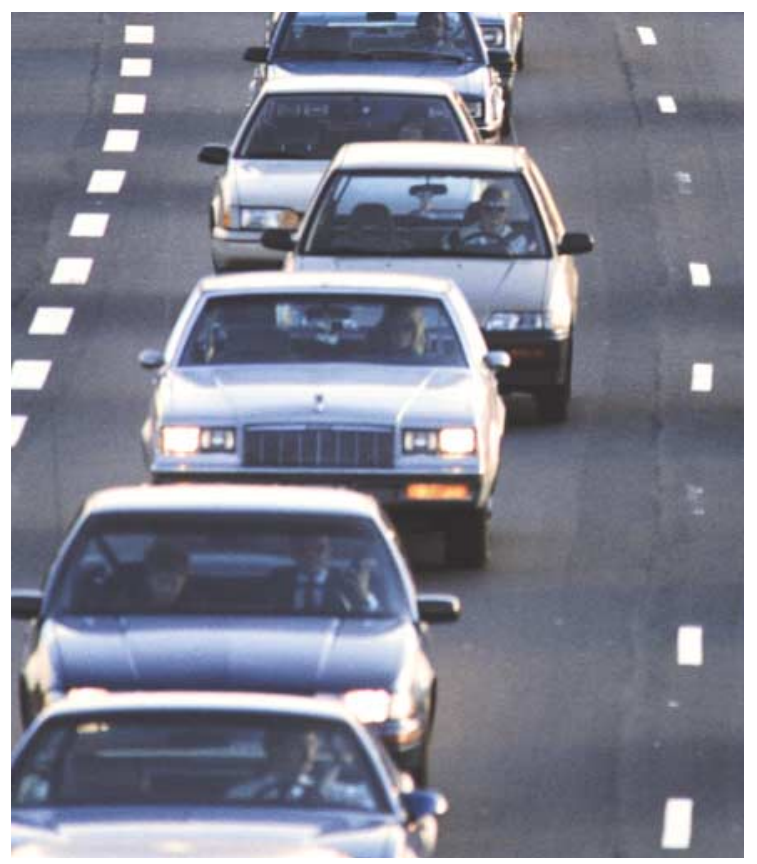

Members of the Bcl-2 family regulate lymphocyte death and lymphocyte numbers, and so are essential for normal lymphocyte development and homeostasis. The pro-apoptotic Bcl-2family members Bak and Bax are central regulators of mitochondrion-dependent cell death, but their roles in T-cell development and homeostasis have not been critically analysed. Rathmell and colleagues now report in Nature Immunology that deficiency of Bak and Bax disrupts these processes, and that T-cell development is inhibited by the accumulation of cells that would normally be deleted by pro-apoptotic Bcl-2-family members.

Mice that are deficient for both Bak and Bax ( $\mathrm{Bak}^{-/-} \mathrm{Bax}{ }^{-/-}$mice) have been generated previously; these animals have several developmental defects resulting from abnormalities in many cell types. To investigate which of the defects are intrinsic to the haematopoietic system, the authors reconstituted lethally irradiated recombinase-activating gene $1(\operatorname{Rag} 1)^{-/-}$ mice (which lack endogenous lymphocytes) with $\mathrm{Bak}^{-1-} \mathrm{Bax}^{-1-}$ bone marrow. After transplantation, thymic reconstitution and peripheral $\mathrm{T}$-cell accumulation were normal in recipients of $\mathrm{Bak}^{-/-} \mathrm{Bax}^{-/-}$bone marrow, but with time, thymocyte development was increasingly disturbed, thymic cellularity decreased and the mice developed splenomegaly.
$B a k^{-1-} B a x^{-/-}$thymocytes showed increased resistance to death induced by dexamethasone, neglect and antigen-receptor signalling. In addition, the elimination of $\mathrm{T}$ cells that responded to superantigens was reduced in $\mathrm{Bak}^{-1} \mathrm{Bax} x^{-1}$ lymphocytes compared with wild-type lymphocytes. These results indicate that Bak and Bax are required for the deletion of cells that have failed to receive positively selecting survival signals, as well as for antigen-specific negative selection; their absence leads to increased numbers of peripheral $\mathrm{T}$ cells, so explaining the splenomegaly that was seen in these mice.

But, how does the resistance of $\mathrm{Bak}^{-/-} \mathrm{Bax}{ }^{-/-}$ thymocytes to apoptosis tie in with the observed decline in thymic cellularity? The reduced thymic cellularity resulted from a progressive decrease in thymopoiesis, which, as peripheral T cells are generated normally in the $\mathrm{Bak}^{-/-} \mathrm{Bax}{ }^{-/}$ reconstituted mice, was not due to an intrinsic defect. So, the authors conclude that cell-extrinsic effects, such as a build-up of cells that do not undergo Bak- and Bax-dependent elimination, result in the disruption of thymopoiesis in the $B a k^{-/-} \mathrm{Bax}^{--} \mathrm{T}$-cell-reconstituted mice.

Jenny Buckland

(Q) References and links

ORIGINAL RESEARCH PAPER Rathmell, J. C. et al. Deficiency in Bak and Bax perturbs thymic selection and lymphoid homeostasis. Nature Immunology 3 September 2002 (DOI 10.1038/ni834)

\title{
New location for hypermutation
}

We assume that somatic hypermutation occurs exclusively in germinal centres, but it seems that autoantibody responses could follow different rules. A new study in Science, by William and co-workers, indicates that autoreactive B cells can proliferate and mutate at an alternative location.

Autoimmune-prone MRL.Fas ${ }^{l p r}$ mice that carry a transgenic immunoglobulin heavy chain were used in this study. These mice have an increased and detectable frequency of B cells that are specific for IgG2a. Such anti-IgG antibodies, which are known as rheumatoid factors (RFs), are typical of autoimmune diseases such as systemic lupus erythematosus.

Although these mice spontaneously produce high levels of RFs that are somatically mutated, William et al. detected few, if any, $\mathrm{RF}^{+}$germinal centres in the mouse spleens. Instead, clusters of rapidly proliferating $\mathrm{RF}^{+} \mathrm{B}$ cells were found to form at the T-zone-red-pulp border.
To test whether $\mathrm{RF}^{+} \mathrm{B}$ cells undergo antigen-driven mutation and selection at this site, $\mathrm{RF}^{+} \mathrm{B}$ cells were microdissected from this site and the immunoglobulin variable $(V \kappa)$ genes were sequenced. This analysis showed that the $\mathrm{RF}^{+} \mathrm{B}$ cells had indeed accumulated mutations, but where did these mutations arise? It remained possible that $\mathrm{RF}^{+} \mathrm{B}$ cells were mutated in rare germinal centres before migrating to the extra-follicular site.

However, neighbouring B cells were found to have closely related patterns of mutation, which indicates that they had arisen from a common precursor and mutated in situ.

It is not clear why the $\mathrm{RF}^{+} \mathrm{B}$ cells shun the specialized microenvironment of the germinal centre. The authors propose that the abundance of self-antigen might prolong the proliferation of B cells at extrafollicular sites, allowing them to reach a threshold number of cell divisions for the initiation of mutation. It is not known whether there might be normal immune responses that follow similar rules.

Jennifer Bell

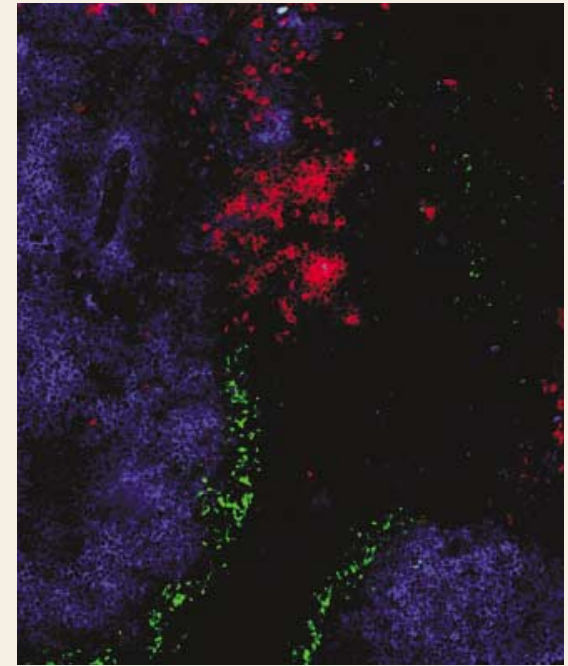

Rheumatoid factor (RF)-producing B cells (red) are located in the marginal sinus (stained green with anti-MOMA1) bridging channels at the border between the T-zone (stained blue with anti-Thy1) and rod pup. The margin anti-Thy 1 and red pulp. The marginal sinus is demarcated by channels. The RF+ $\mathrm{B}$ cells proliferate and mutate at this site.

(4) References and links ORIGINAL RESEARCH PAPER William, J. et al. Evolution of autoantibody responses via somatic hypermutation outside of germinal centers. Science 297, 2063-2066 (2002) WEB SITE

Mark Shlomchik's lab: http://info.med.yale.edu/ Mark Shlomchik's lab: http://in
immuno/fac_shlomchik.html 